\title{
Does a waiting time for elective coronary angioplasty affect the primary success rate?
}

\author{
Karel T Koch, Jan J Piek, George K David, Karla Mulder, Ron J G Peters, Kong I Lie
}

\begin{abstract}
Objective-To evaluate the effect of the waiting time for elective percutaneous transluminal coronary angioplasty (PTCA) on the primary success rate.

Setting-University hospital in The Netherlands.

Patients-A cohort of 817 consecutive patients awaiting elective PTCA. Scheduled PTCA was performed in all 817 patients, involving 1237 coronary lesions. Main outcome measures-The relation between procedural success and the duration of the waiting time was evaluated. Major cardiac events, that is, death and myocardial infarction while awaiting PTCA, were documented. Alterations in lesion characteristics during the waiting time were assessed in unsuccessful procedures.
\end{abstract}

Results-Elective PTCA was performed within one to six weeks after acceptance in 388 patients (587 lesions; $47 \cdot 5 \%)$, between six and 12 weeks in 203 patients (308 lesions; 25\%), and after more than 12 weeks in 226 patients (342 lesions; $27 \cdot 5 \%$ ). The procedural success rates in the defined time intervals were $97 \%, 99 \%$, and 97\% in ACC/AHA type A lesions, 93\%, $87 \%$ and $90 \%$ in type $B$ lesions, and $63 \%$, $55 \%$ and $38 \%$ in type $C$ lesions respectively; $96 \%$ of type $C$ lesions were total coronary occlusions. There was a significant decrease in primary success rate in type $C$ lesions after a waiting time beyond 12 weeks. A reasonable explanation for an unsuccessful angioplasty related to alterations in lesion characteristics during the waiting time was documented in only four of 115 procedures.

Conclusions-The primary success in type $A$ and $B$ lesions is unaffected by the duration of a waiting period for elective PTCA. A waiting time of more than 12 weeks is associated with a lower success rate in patients with total coronary occlusions.

(Heart 1997;77:432-436)

Keywords: angioplasty; waiting time; patient selection; coronary artery disease

In health care systems that operate under limited budgets, financial restrictions may lead to waiting times for resource intensive cardiovascular procedures. ${ }^{12}$ There is a tendency to use waiting times as criteria for evaluating and criticising national health care systems. ${ }^{3-5}$ There are limited data available on the consequences of waiting times, and their effects on the quality of medical care..$^{6-8}$

At our centre, the discrepancy between the number of referred patients and the facilities for performing percutaneous transluminal coronary angioplasty (PTCA) has resulted in waiting times for angioplasty frequently exceeding more than three months in the past years. The purpose of this study was to evaluate the effect of the waiting time for elective PTCA on the primary success rate of the procedure.

\section{Methods}

The study group consisted of 817 consecutive patients entered on our waiting list registry after acceptance for elective PTCA between January 1990 and January 1992. During this period we were confronted with increasing waiting times for PTCA. Angioplasty was performed in all 817 patients, involving a total of 1237 coronary lesions. According to the unmodified ACC/AHA criteria, ${ }^{9} 405$ coronary lesions (32\%) were classified as type A, 631 (51\%) as type B, and $201(17 \%)$ as type C (figure). This classification was based on the angiogram performed before the procedure. Procedural success was defined as less than $50 \%$ residual stenosis without major cardiac events, that is, death, coronary artery bypass grafting operation, acute myocardial infarction, or repeat angioplasty within 24 hours. Myocardial infarction was defined as a creatine kinase $M B$ rise of more than twice the upper limit of normal.

The waiting time was defined as the time period from the day the patient was accepted for angioplasty until the day of the procedure itself. The diagnostic angiogram was performed within one week of acceptance for PTCA in $97.8 \%$ of patients. In the remaining $2 \cdot 2 \%$ of the patients, the diagnostic angiogram was performed within six weeks of final acceptance. Patients with unstable angina ${ }^{10}$ and patients in whom acceptance for angioplasty was not based on a recent coronary angiogram were excluded.

A lesion was considered totally occluded when there was an interruption of the continuity in the angiographic appearance of a coronary artery without antegrade flow. The duration of an occlusion was determined from angiographic data or estimated from an index clinical event such as a myocardial infarct or a 

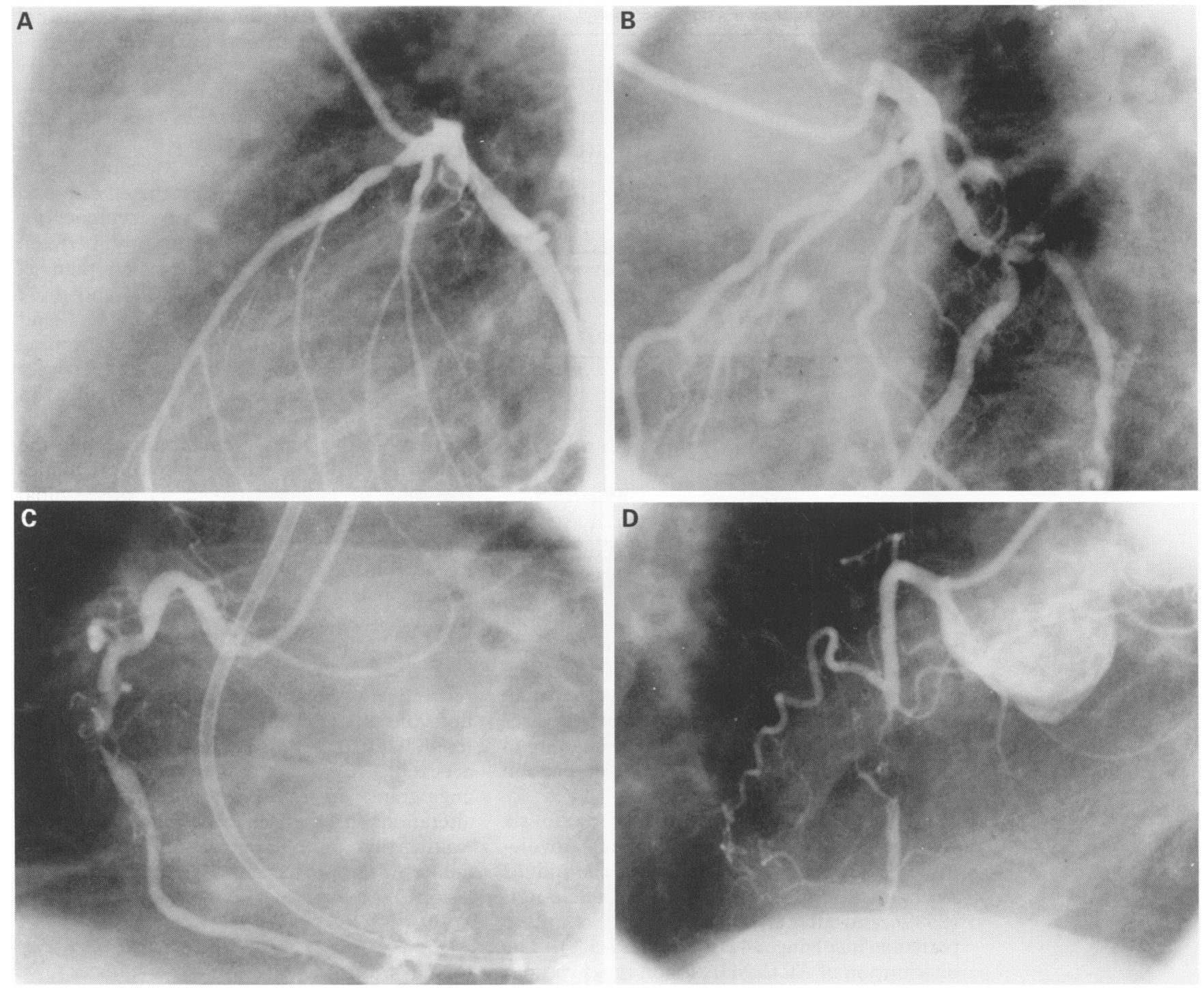

Illustrations of lesion types according to the ACC/AHA classification. (A) Angiography of the left coronary artery, left lateral view, showing a proximal concentric lesion of the left anterior descending coronary artery classified as a type $A$ lesion. (B) Angiography of the left coronary artery, left oblique view, showing an eccentric lesion of the left circumflex coronary artery with a sidebranch originating from the lesion, classified as a type $B$ lesion.

(C) Angiography of the right coronary artery, left oblique view, showing an eccentric lesion with proximal tortuosity, classified as a type B lesion.

(D) Angiography of the right coronary artery, left oblique view, showing a total coronary occlusion with bridging collateral, classified as type C.

marked change in anginal pattern. The selection of patients and their priority on the waiting list was left to the discretion of the attending interventional cardiologists and depended upon varying criteria, such as functional class of angina, progression of symptoms, or the results of non-invasive testing.

\section{OUTCOME MEASURES}

The relation was assessed between procedural success and the duration of the waiting time. The waiting time was divided arbitrarily in three time intervals, that is, less than six weeks, six to 12 weeks and more than 12 weeks, as these time periods were considered relevant for patient management. ${ }^{11} 12$ The incidence of death and myocardial infarction on the waiting list was verified at time the patients were scheduled for the actual procedure. The angiograms of 115 unsuccessfully treated lesions were compared with the initial angiogram in order to evaluate alterations in lesion characteristics during the waiting time that could have been responsible for failure of the procedure.
STATISTICS

Continuous variables were expressed as mean (SD). A $\chi^{2}$ test was used to compare dichotomous variables, Student's $t$ test for continuous variables; a $P$ value less than 0.05 was considered significant.

\section{Results}

The demographic data of the patients are summarised in table 1 . The clinical information on the study patients was complete at the time of the actual procedure. All patients accepted for PTCA were actually scheduled for the procedure, and underwent angioplasty. During the waiting time (mean 8.8 weeks, range 1 to 42 ), there were no deaths and no patients experienced an acute myocardial infarction.

The overall procedural success rate in the 817 patients was $87 \cdot 9 \%$ (718 patients). Procedural complications included mortality in one patient $(0.1 \%)$, coronary bypass surgery performed in five patients $(0 \cdot 6 \%)$, and acute myocardial infarction found in 20 patients 
Table 1 Patient characteristics, 817 patients

\begin{tabular}{lcc}
\hline Mean (SD) age (years) & $60 \cdot 4$ & $(10 \cdot 1)$ \\
Female & 229 & $(28 \%)$ \\
Male & 588 & $(72 \%)$ \\
Risk factors & & \\
$\quad$ Family history & 155 & $(19 \%)$ \\
$\quad$ Hypercholesterolaemia & 269 & $(33 \%)$ \\
$\quad$ Smokers & 351 & $(43 \%)$ \\
Hypertension & 277 & $(34 \%)$ \\
Diabetes & 114 & $(14 \%)$ \\
Previous myocardial infarction & 375 & $(46 \%)$ \\
Previous PTCA & 212 & $(26 \%)$ \\
Previous CABG & 65 & $(8 \%)$ \\
\hline
\end{tabular}

CABG, coronary artery bypass grafting; PTCA, percutaneous transluminal coronary angioplasty.

Table 2 Procedural result in 817 patients, 1237 lesions

\begin{tabular}{lrl}
\hline PTCA success (all) & 718 & $(87 \cdot 9 \%)$ \\
Mortality & 1 & $(0 \cdot 1 \%)$ \\
CABG (within 24 hours) & 5 & $(0 \cdot 6 \%)$ \\
MI (CK-MB > 2 upper limit) & 20 & $(2 \cdot 5 \%)$ \\
Repeat PTCA (within 24 hours) & 5 & $(0 \cdot 6 \%)$ \\
Unsuccessful, uncomplicated & 68 & $(8 \cdot 3 \%)$ \\
Success in 1237 lesions: & & \\
Type A & $396 / 405$ & $(98 \%)$ \\
Type B & $575 / 631$ & $(92 \%)$ \\
Type C & $111 / 201$ & $(55 \%)$ \\
\hline
\end{tabular}

CABG, coronary artery bypass grafting; CK-MB, creatine kinase-MB; MI, myocardial infarction; PTCA, percutaneous kinase-MB; MI, myocardial infarction
transluminal coronary angioplasty.

(2.5\%). Repeat angioplasty within 24 hours was performed in five patients $(0.6 \%)$. The remaining 68 procedures $(8.3 \%)$ were unsuccessful but uncomplicated. In almost all cases failure of the procedure was due to inability to cross the lesion with a guidewire or balloon (table 2)

PTCA was performed within one to six weeks after acceptance in 388 patients, involving 587 lesions $(47 \cdot 5 \%)$, between six and 12 weeks in 203 patients, involving 308 lesions $(25 \%)$, and after more than 12 weeks in 226 patients, involving 342 lesions $(27 \cdot 5 \%)$. The distribution of ACC/AHA lesion types was not significantly different between these waiting time intervals (one to six, six to 12 , and more than 12 weeks, respectively: table 3 ).

Table 3 Waiting time distribution of lesion types

\begin{tabular}{lrrrl}
\hline & \multicolumn{3}{l}{ Waiting time } & \\
\cline { 2 - 5 } & $1-6$ weeks & $6-12$ weeks & $>12$ weeks & All \\
\hline Type A & $211(35 \%)$ & $103(33 \%)$ & $91(25 \%)$ & $405(32 \%)$ \\
Type B & $284(48 \%)$ & $146(47 \%)$ & $201(58 \%)$ & $631(51 \%)$ \\
Type C & $92(17 \%)$ & $59(19 \%)$ & $50(16 \%)$ & $201(17 \%)$ \\
\hline
\end{tabular}

Table 4 Procedural success related to waiting period

\begin{tabular}{llll}
\hline \multirow{2}{*}{ Waiting period } & \multicolumn{4}{l}{ Successful/total number of lesions (\%) } \\
\cline { 2 - 4 } & $1-6$ weeks & $6-12$ weeks & $>12$ weeks \\
\hline Type A & $206 / 211(97 \%)$ & $102 / 103(99 \%)$ & $88 / 91(97 \%)$ \\
Type B & $266 / 284(93 \%)$ & $128 / 146(87 \%)$ & $181 / 201(90 \%)$ \\
Type C & $59 / 92(63 \%)^{\star}$ & $33 / 59(55 \%)^{\star}$ & $19 / 50(38 \%)^{\star}$ \\
\hline${ }^{\star} \chi^{2}$ for trend: $\mathrm{P}<0.005$.
\end{tabular}

Table 5 Type C lesions: percentage of total occlusions and estimated duration of occlusion at the time of acceptance for PTCA

\begin{tabular}{llll}
\hline & \multicolumn{3}{l}{$\begin{array}{l}\text { Duration of occlusion at } \\
\text { acceptance for PTCA }\end{array}$} \\
\cline { 2 - 4 } Waiting time & $\begin{array}{l}\text { Total occlusions } \\
\text { (\% of C lesions) }\end{array}$ & Mean & (SD) (weeks) \\
\hline <6 weeks & $97 \%$ & $20 \cdot 1$ & $(15 \cdot 2)$ \\
6-12 weeks & $96 \%$ & $21 \cdot 4$ & $(12 \cdot 5)$ \\
$>12$ weeks & $96 \%$ & $20 \cdot 8$ & $(14 \cdot 4)$ \\
& NS & NS & \\
\hline
\end{tabular}

PTCA, percutaneous transluminal coronary angioplasty.
In type $\mathrm{A}$ and $\mathrm{B}$ lesions, the waiting time did not influence the primary success rate significantly. In type $C$ lesions, a decrease in primary success rate could be shown beyond a waiting time of more than 12 weeks (less than 12 weeks $v$ more than 12 weeks: $\mathrm{P}=0.005$, table 4). Of all type $C$ lesions, $96 \%$ were total coronary occlusions. The mean estimated duration of the occlusion at the time of acceptance for PTCA did not differ significantly between patients with a waiting period of less than six weeks, between six and 12 weeks, and more than 12 weeks (table 5).

The angiograms before and after a waiting period of 115 unsuccessful procedures were reviewed and compared. In 90 of these 115 procedures, a total coronary occlusion was present at the time of acceptance and the artery could not be successfully recanalised a the time of angioplasty. In 21 procedures, PTCA was unsuccessful because of miscellaneous factors (such as urgent bypass surgery, major side branch occlusion, or inability to obtain a less than $50 \%$ residual stenosis) which could not be attributed to lesion alterations during the waiting time. In four procedures (after 3, 7, 8, and 13 weeks, respectively), a total coronary occlusion with unfavourable features for PTCA was encountered, while these lesions appeared to be easily accessible for angioplasty on the initial angiogram. In these cases, we considered alterations in lesion characteristics during the waiting time to be the most likely cause of the failure of the procedure (inability to cross the lesion).

\section{Discussion}

This study shows that the procedural success rate of elective coronary angioplasty is not influenced by the waiting time in type A and B lesions, while there is a significant decrease in procedural success rate in type $\mathrm{C}$ lesions beyond a waiting time of more than 12 weeks. This could not be explained by angiographic alterations in lesion characteristics during this period, as it was noted in only four of 115 failures. To our knowledge, no study has so far reported on the effects of waiting times on the procedural result of percutaneous coronary intervention.

The results of the present study indicate that the procedural success in type $A$ and $B$ lesions is unaffected by the waiting time for coronary intervention with a mean duration of 8.8 weeks. This observation suggests that the priority to perform angioplasty should be based on clinical symptoms rather than on the angiographic characteristics of the coronary lesion. This contrasts to the situation in type $C$ lesions. In comparison with type $A$ and $B$ lesions, the procedural result after a waiting time of more than 12 weeks was significantly worse in type C lesions, almost all (96\%) being total occlusions.

Many studies have indicated that the duration of the coronary occlusion is a key factor for success of angioplasty, ${ }^{13-15}$ although others could not demonstrate such a relation. ${ }^{16}$ After a 
waiting period of less than 12 weeks, the procedural results in type $\mathrm{C}$ lesions in the present study are in accordance with the results reported in the literature (percentage success ranging from $47 \%$ to $73 \%) .{ }^{1517}$ However, there was a marked decrease in success rate beyond a waiting time of more than 12 weeks. The lower success rate in total coronary occlusions was associated with an additional time awaiting the procedure, since the estimated duration of occlusion at the time of acceptance for PTCA, was similar in the three waiting time categories (table 5). In our view, these patients are to be given priority, irrespective of the clinical symptoms - which are often mild due to marked development of collateral vessels in chronic coronary occlusion. ${ }^{18}$ This patient management is particularly important, since it has been shown that successful recanalisation of total occlusions may reduce the need for coronary bypass surgery. ${ }^{19-21}$

Data on the effects of waiting lists on coronary revascularisation procedures are limited. Mortality rates of $2 \cdot 2 \%$ to $0.4 \%$ have been reported after mean waiting times of 42 and 17 days, respectively 2223 in patients on the waiting list for coronary bypass surgery. Recently, Chester et al ${ }^{24}$ stated that adverse events, that is, myocardial infarction, unstable angina, and angiographic total occlusion, were not uncommon while awaiting PTCA. This contrasts with our study, in which there were no deaths or myocardial infarctions on the waiting list. The incidence of angiographic occlusion in our study appears small, although this was only studied as far as it adversely affected the procedural result. Another difference is that the waiting times evaluated in our study were considerably shorter than those described by Chester et al. In their study, every procedure performed within three months was considered urgent, while the median waiting time was eight months, ranging from three to 27 months, as compared to $8 \cdot 8$ weeks, ranging from one to 42 weeks, in the present study.

All patients who entered the waiting list during the study period underwent the procedure after a relatively short mean waiting time. The patients awaiting angioplasty were frequently seen by their attending cardiologists and prioritised in case of progression of anginal symptoms. This careful monitoring of the patients is the most probable reason that the cohort of patients was complete in our study. This completeness of follow up differs from the report of Chester $e t a l$, and is possibly also related to the differences in waiting times. However, even after a median duration of eight months (range, one to 42 months) the number of patients lost during follow up in their study was rather small: one patient had a fatal myocardial infarction and four patients (2\%) were lost.

\section{LIMITATIONS OF THE STUDY}

The decision to place a patient on the waiting list, or to change priority during the waiting time, was at the discretion of the interventional cardiologist at the time the patient was accepted for angioplasty, and the attending cardiologist in charge of the patient while the patient was awaiting PTCA. We did not evaluate these clinical decisions. This certainly may have introduced clinical bias, which nevertheless reflects common clinical practice.

In this study, we used the ACC/AHA lesion morphology classification system, ${ }^{9}$ which is subject to criticism for many reasons, especially when used for the estimation of procedural success and risks. ${ }^{1725} \mathrm{We}$ considered it appropriate for the purpose of our study, since it was the only generally applied classification system by the time our data were collected.

It is difficult to estimate the duration of coronary occlusion on the basis of clinical information. This drawback in the methodology applies to all three patient categories, suggesting that the observed differences in the result of PTCA in the three patient groups are related to differences in waiting time. However, we cannot exclude the possibility that differences between the patient groups were already present at the time of acceptance.

The results of this single centre experience warrant confirmation by other investigators. The present study is an observational study: randomisation of waiting times may yield a more definitive answer regarding the effects of waiting times on procedural success.

The angiographic alterations in lesion morphology were only studied in unsuccessful procedures; thus the study yields no general information on progression of coronary artery disease during waiting times.

\section{CONCLUSION}

The primary success rate in type A and B lesions is unaffected by the duration of a waiting period for elective coronary angioplasty; a waiting time of more than 12 weeks is associated with a lower success rate in type C lesions. Alterations in lesion morphology that adversely affect procedural outcome are rare during the waiting time. The results of angioplasty in type $C$ lesions may be improved by prioritisation based on angiography, irrespective of the clinical presentation.

We gratefully acknowledge Rob Zuiker for assistance during the study, and Martin H Prins from the Department of Biostatistics and Clinical Epidemiology (chief: Jan G P Tijssen) for statistical advice. We would also like to thank the technical and nursing staff of our cardiac catheterisation laboratory (chief: Peter Belgraver) for skilled assistance.

1 Marber M, MacRea C, Joy M. Delay to invasive investigation and revascularisation for coronary heart disease in South West Thames region: a two tier system? BMF 1991;302:1189-91.

2 Cheitlin MD. 23rd Bethesda Conference: access to cardiovascular care. $\mathcal{F}$ Am Coll Cardiol 1992;19:1477-85.

3 Carrol RJ, Horn SD, Soderfeldt B, James BC, Malmberg $\mathrm{L}$. International comparison of waiting times for selected cardiovascular procedures. F Am Coll Cardiol 1995;25

Sullivan P. The AMA looks north with fear and loathing Can Med Assoc f 1990;142:50-1

5 Harvey LK. AMA Survey of Public Opinion on Health Care Issues. Chicago: American Medical Association, 1991

6 Weissmann JS, Stern R, Fielding SL, Epstein AM. Delayed access to health care: risk factors, reasons and consequences. Ann Intern Med 1991;114:325-31.

Bindman AB, Grumbach K, Keane D, Rauch L, Lucew JM. Consequences of queuing for care at a public hospital emergency department. FAMA 1991;266:1091-6.

8 Ryan TJ. International comparisons of waiting times for selected cardiovascular procedures: a commentary on the long queue [editorial]. $\mathcal{f} \mathrm{Am}$ Coll Cardiol 1995;25:564-6.
Ryan TJ, Faxon DP, Gunnar RP, and the ACC/AHA Task 
Force. Guidelines for percutaneous transluminal angioplasty. F Am Coll Cardiol 1988;12:529-45.

10 Braunwald E. Unstable angina, a classification. Circulation 1989;80:410-4

11 Naylor CD, Baigrie RS, Goldman BS, Basinski A, Revascularisation Panel, Consensus Methods Group. Assessment of priority for coronary revascularisation proAssessment of priority for coronary

12 Naylor CD, Baigrie RS, Goldman BS, Beanlands DS Berman N, Borts D, et al. Assigning priority to patients Berman N, Borts D, et al. Assigning priority to patien ples from a panel of cardiologists and cardiac surgeons. ples from a panel of cardiolog

13 Maiello L, Colombo A, Gianrossi R, Mutinelli M, Bouzon $\mathrm{R}$, Thomas J, et al. Coronary angioplasty of chronic tota occlusions: factors predictive of procedural success. $A m$ Heart f 1992,124:581-4.

14 Tan W, Sulke AN, Taub NA, Watts E, Sowton E. Determinants of success of coronary angioplasty in patien with a chronic total occlusion: a multiple logistic regres sion model to improve selection of patients. Br Heart $f$ 1993;70:126-31.

15 Puma JA, Sketch MH, Tcheng JE, Harrington RA, Phillips HR, Stack RS, et al. Percutaneous revascularisation of chronic coronary occlusions: an overview. $f \mathrm{Am} C \mathrm{Coll}$ Cardiol 1995;26:1-11.

16 Stone GW, Rutherford BD, McConahay DR, Johnson WR, Giorgi LV, Ligon RW, et al. Procedural outcome of angioplasty of chronic total occlusion: an analysis of 971 lesions in 905 patients. 7 Am Coll Cardiol 1990;15: $849-56$.

17 Ellis GE, Vandormael MG, Cowley MJ, DiSciascio G Deligonul U, Topol EJ, et $a l$, and the Multivessel Deligonul U, Topol EJ, et al, and the Multivess Angioplasty Prognosis Study Group. Coronary morpho- cations for patients selection. Circulation 1990;82: 1193-202.

18 Rentrop KP, Feit F, Sherman W, Thornton JC. Serial assessment of coronary artery obstruction and collateral
flow in acute myocardial infarction. Report from the Second Mount Sinai-New York University Reperfusion Trial. Circulation 1989;80:1166-75.

19 Bell MR, Berger PB, Bresnahan JF, Reeder GS, Bailey KR, Holmes DR. Initial and long-term outcome of 354
Hol Holmes DR. Initial and long-term outcome of 354
patients after coronary balloon angioplasty of chronic patients after coronary balloon angioplasty

20 Ivanhoe RJ, Weintraub WS, Douglas JS, Lembo NJ, Furman M, Gershony G, et al. Percutaneous transluminarman $M$, Gershony $G$, et al. Percutaneous transluminal coronary angioplasty of chronic total occlusions: primary success, restenosis and

21 Warren RJ, Black AJ, Valentine PA, Manolas EG, Hunt D. Coronary angioplasty for chronic total occlusion reduces the need for subsequent coronary bypass surgery. $\mathrm{Am}$ Heart $\mathcal{F} 1990 ; 120: 270-4$

22 Suttorp MJ, Kingma JH, Vos J, Koomen EM, Tijssen JPG, Vermeulen FEE, et al. Determinants for early mortality in patients awaiting coronary artery bypass graft surgery: a case-control study. Eur Heart F 1992;13:238-42.

23 Naylor CD, Sykora K, Jaglal SB, Jefferson S, and the Steering Committee of the Adult Cardiac Care Network of Ontario. Waiting for coronary artery bypass sur population-based study of 8517 consecutive patients in Ontario, Canada. Lancet 1995;346:1605-9.

24 Chester M, Chen L, Kaski JC. Identification of patients at high risk for adverse coronary events while awaiting routine coronary angioplasty. Br Heart $\mathcal{f}$ 1995;73:216-22.

25 Myler RK, Shaw RE, Stertzer SH, Hecht HS, Ryan C, Rosenblum J, et al. Lesion morphology and coronary angioplasty: current experience and analysis. $\mathcal{f} \mathrm{Am} \mathrm{Coll}$ Cardiol 1992;19:1641-52. 